\title{
Avaliação do chá branco como potencial inibidor de corrosão
}

\author{
Evaluation of white tea as a potential \\ corrosion inhibitor
}

Thamires Matos de Oliveira ${ }^{1}$, Sheila Pressentin Cardoso ${ }^{1}$

\begin{abstract}
${ }^{1}$ Instituto Federal do Rio de Janeiro - IFRJ, campus Nilópolis. Rua Coronel Délio Menezes Porto n ${ }^{\mathrm{o}}$ 1045, CEP: 26530060, Centro, Nilópolis, Rio de Janeiro, Brasil.

e-mail: thamires.qpn@bol.com.br, shepressentin@gmail.com.
\end{abstract}

\section{RESUMO}

O trabalho apresenta avaliação do extrato alcoólico do chá branco como potencial inibidor de corrosão para o aço carbono P110 na presença de ácido clorídrico 1 mol. $\mathrm{L}^{-1}$. Os inibidores de corrosão destacam-se na proteção de peças metálicas em ambientes ácidos, sendo que muitas das substâncias presentes na composição de inibidores comerciais apresentam caráter danoso ao meio ambiente. Por este motivo, extratos de plantas passaram a ser avaliados como potenciais inibidores de corrosão pela sua natureza não tóxica ao meio ambiente, além de seu caráter renovável, constituindo-se nos chamados inibidores verde de corrosão. O chá branco é proveniente da Camellia sinensis, sendo utilizadas folhas e galhos secos na preparação do extrato em etanol. Foram realizados ensaios de perda de massa para diferentes concentrações do extrato (100, 200 e 300 ppm), com a concentração de 300 ppm apresentando o melhor resultado, com uma eficiência de inibição de $90,2 \%$. Ensaios de polarização e impedância eletroquímica foram realizados com redução nas correntes anódicas e catódicas, aumento na resistência a transferência de carga e redução na capacitância da dupla camada elétrica, indicando um processo de adsorção do extrato sobre as áreas ativas do metal. Os resultados apontam para o potencial uso de extrato alcoólico do chá branco como matéria ativa na formulação de inibidor de corrosão ambientalmente seguro.

Palavras-chave: inibidor de corrosão, inibidor verde, chá branco, Camellia sinensis.

\begin{abstract}
This research work presents an evaluation of the alcoholic extract of the white tea as potential corrosion inhibitor for the carbon steel P110 in the presence of $1 \mathrm{~mol} . \mathrm{L}^{-1}$ hydrochloric acid. Corrosion Inhibitors stand out in the protection of metallic parts in acid environments, and many of the substances present in the composition of the commercial inhibitors are harmful to the environment. For this reason, plant extracts began to be evaluated as potential corrosion inhibitors because of their non toxic nature, as well as their renewable character, constituting the so called green corrosion inhibitors. The white tea comes from the Camellia sinensis, leaves and dry branches are used in the preparation of the extract in ethanol. Mass loss tests were performed for different concentrations of the extract $(100,200,300 \mathrm{ppm})$ with the concentration of $300 \mathrm{ppm}$ showing the best result, with an inhibition efficiency of $90,2 \%$. Polarization and electrochemical impedance tests were carried out with reduction in the anodic and cathodic currents, increase in the resistance to charge transfer and reduction in the capacitance of the electric double layer, indicating a process of adsorption of the extract over the active areas of the metal. The results indicate the potential use of the alcoholic extract of white tea as an active material in the formulation of an environmentally safe corrosion inhibitor.
\end{abstract}

Keywords: corrosion inhibitor, green inhibitor, white tea, Camellia sinensis.

\section{INTRODUÇÃO}

Sendo a corrosão um processo espontâneo, que modifica o material metálico fazendo com que este perca sua durabilidade e desempenho, seu estudo e controle requerem atenção constante, tornando-se um dos problemas da sociedade moderna. Segundo JACKSON [1], os custos previstos com a corrosão nos EUA foram de US\$ 1 trilhão para o ano de 2013, subindo para US\$ 1,1 trilhão até o final de 2016, equivalendo a 
6,2\% do PIB americano. Estima-se que nos demais países os processos corrosivos também comprometam parte do PIB, gerando, além dos gastos, a possibilidade de acidentes devido ao degaste ou falha em equipamentos e estruturas metálicas trazendo prejuízos para o homem e a natureza.

Nos processos industriais os ácidos clorídrico, sulfúrico, fosfórico e nítrico estão entre os mais utilizados na limpeza e no tratamento da superfície dos aços [2]. Apesar da ação desejada ser a dissolução dos óxidos de ferro, que constitui a ferrugem e calamina, esses ácidos corroem o metal com o desprendimento de hidrogênio acarretando inúmeros inconvenientes [3]. Nesses casos, o método de proteção mais usado consiste no emprego de inibidores de corrosão, ocorrendo a formação de um filme protetor sobre as regiões catódicas e/ou anódicas da superfície metálica devido ao processo de adsorção entre o inibidor e o metal. Esses inibidores (de adsorção) são compostos orgânicos possuidores de insaturações e/ou grupamentos fortemente polares contendo nitrogênio, oxigênio ou enxofre.

No início do século XXI, o uso de produtos naturais como possíveis inibidores de corrosão passou a ser tema recorrente em estudos, principalmente por aliarem baixo custo de produção a um bom desempenho na redução da velocidade dos processos corrosivos em diferentes ligas, além do caráter não tóxico ao meio ambiente (salvo algumas exceções), sendo biodegradáveis e provenientes de um recurso natural renovável [4], agregando ao seu uso não só fatores ambientais como econômicos. Além disso, estudos indicam que essas substâncias apresentam baixa toxidade ao meio ambiente, quando comparadas com inibidores utilizados atualmente [5]. A partir desta premissa, surge a possibilidade do uso de produtos naturais como matéria ativa na formulação de inibidores de corrosão.

A literatura apresenta trabalhos que estudam as propriedades anticorrosivas de metabólitos presentes em plantas, sendo os produtos testados de uso comum, como a berinjela [6], além da laranja, manga, tabaco, pimenta preta, cafeína e nicotina [7], com excelentes taxas de inibição, sem dano ambiental e com baixo custo. Todos os trabalhos apresentam excelentes resultados de inibição, particularmente em baixas temperaturas, com destaque para a necessidade de se identificar a concentração crítica do extrato visando obter a máxima proteção possível. A eficiência dos extratos de plantas está associada ao efeito sinérgico decorrente da presença dos metabólitos, tais como alcaloides, flavonoides, taninos, celulose, polissacarídios e polifenóis [7, 8].

Este trabalho visa contribuir nas discussões sobre o tema, tendo como objetivo avaliar a eficiência de inibição do extrato alcoólico (etanol) do chá branco como potencial matéria ativa na formulação inibidor de corrosão para o aço carbono P110 na presença de ácido clorídrico $1 \mathrm{mol.L} \mathrm{L}^{-1}$

O chá branco é proveniente da Camellia sinensis, planta que pertence à família: Theaceae, espécie: Camellia sinensis (L.) Kuntze [9]. A planta é cultivada em mais de 30 países, contendo em sua composição substâncias orgânicas como polissacarídios, óleos voláteis, vitaminas, minerais, alcalóides (cafeína) e polifenóis (catequinas, flavonoides, antocianinas e ácido fenólico) [10].

Quatro tipos diferentes de chás podem ser obtidos a partir da Camellia sinenses: o chá branco, o chá verde, o chá preto e o chá oolong. A diferença entre esses chás está no tipo de processamento de secagem ao qual cada um é submetido, levando a distintos graus de oxidação. O chá branco é feito com flores e folhas mais jovens e menos processadas, apresentando coloração mais branda e sabor mais agradável. Na obtenção do chá verde as folhas passam por um processo de cozimento após murcharem, sendo enroladas e colocadas para secar a sombra. O chá oolong possui um processamento intermediário, onde as folhas de Camellia sinensis sofrem lesões mecânicas, sendo brevemente oxidadas e secas ao final. Já o chá preto tem um processo de obtenção semelhante ao do chá oolong, só que sua oxidação é mais intensa que a presente nos outros chás, havendo a queima de suas folhas [11]. Os polifenóis da classe dos flavonoides, dentre os quais se destacam as catequinas, são os principais metabólitos presentes nas folhas da Camellia sinensis, sendo encontrados em todos os seus tipos de chás [12]. O chá branco também apresenta elevada concentração de alcaloides (principalmente a cafeína), ácido gálico e cumárico [13], enquanto os chás verde, oolong e preto se destacam pela presença de catequinas e teaflavinas em diferentes concentrações, devido aos diferentes processos de oxidação ao qual são submetidos. Sendo assim, o chá verde contém alta concentração de catequinas e baixa concentração de teaflavinas, com o chá oolong apresentando quantidades intermediárias desses compostos, enquanto o chá preto é constituído por uma elevada concentração de teaflavinas e baixa concentração de catequinas [14].

$\mathrm{Na}$ literatura encontram-se trabalhos referentes à utilização de extratos de Camellia sinensis como inibidores de corrosão. Dentre os chás provenientes desta planta, o extrato aquoso do chá verde foi testado como inibidor de corrosão para o aço carbono na presença de $\mathrm{H}_{2} \mathrm{SO}_{4}$ diluído, apresentando eficiência de inibição de até 94\% [10]; para o aço carbono em solução aquosa contendo $\mathrm{NaCl}$ e $\mathrm{Al}_{2}\left(\mathrm{SO}_{4}\right)_{3}$, revelando uma eficiência de inibição de $90 \%$ [15], e para o latão na presença de $\mathrm{Na}_{2} \mathrm{SO}_{4}$, com eficiência de inibição de $79 \%$ [16]. Extratos não aquosos do chá verde também foram testados, com destaque para o emprego do extrato em 
etanol na inibição da corrosão do aço duplex na presença de $\mathrm{HNO}_{3}$, que apresentou eficiência de inibição de até $61,99 \%$ [17], e para o extrato em ácido sulfúrico como inibidor de corrosão do alumínio na presença de $\mathrm{HCl}$, revelando uma eficiência de inibição de 90,5\% [18].

Em todos os casos os extratos do chá verde foram eficientes na inibição do processo corrosivo envolvendo extratos obtidos a partir de solventes distintos (água, etanol e ácido sulfúrico), na proteção de metais diferentes (aço carbono, latão, aço inoxidável e alumínio), em ambientes ácidos ou neutros (ácido sulfúrico, nítrico, clorídrico e salino), com a eficiência sendo atribuída ao efeito sinérgico oriundo da presença de vários compostos químicos que se adsorvem sobre a superfície metálica. Dentre esses compostos destacam-se os polifenóis, como os flavonoides, catequinas e taninos. Já o chá preto foi testado como inibidor de corrosão para o cobre, apresentando uma eficiência de inibição na faixa de $92 \%$ na presença de $\mathrm{NaCl}$ [19].

No caso específico do chá branco, objeto deste estudo, TEIXEIRA et al. [20] avaliaram a eficiência do extrato aquoso do chá branco como inibidor de corrosão para o aço carbono $1020 \mathrm{em} \mathrm{HCl} 1 \mathrm{~mol} . \mathrm{L}^{-1}$, sendo verificado que o extrato acarreta redução no processo corrosivo, com valores de eficiência de inibição de até $89 \%$, sendo identificada a presença de flavonoides como epicatequina e derivados da cafeína no extrato.

Os resultados positivos observados para o chá verde e o chá preto, e o pouco estudo envolvendo o chá branco, levaram à seleção deste para análise como potencial inibidor de corrosão, dando o caráter relevante a esta pesquisa ao analisar o extrato alcoólico do chá branco.

\section{MATERIAIS E MÉTODOS}

A avaliação do extrato alcoólico do chá branco, como potencial inibidor de corrosão para o aço carbono P110 na presença de $\mathrm{HCl}$ foi realizada mediante sua eficiência de inibição, com a realização de ensaios de perda de massa aliados as informações provenientes dos ensaios de polarização e impedância eletroquímica.

Para a obtenção do extrato utilizou-se uma massa de 10 gramas de folhas e talos secos do chá branco (sem preparação prévia e adquiridas em lojas de chás e produtos naturais), que foram adicionadas a um refil de papel de filtro confeccionado para extração a quente em um aparelho tipo Soxhlet (Figura 1a). Foram realizadas extrações com solventes de polaridade crescente: hexano, acetato de etila e etanol. O uso de solventes com polaridade crescente teve como objetivo a obtenção de frações de extrato do chá branco contendo substâncias de natureza química diversa, com as frações em hexano e acetato de etila sendo utilizadas em outra pesquisa. Para cada um dos solventes foi usado um volume de $400 \mathrm{~mL}$, sendo o tempo de extração de oito horas por um período de cinco dias. Em cada troca de solvente a massa residual obtida da extração anterior foi seca, ao ar livre, por $48 \mathrm{~h}$ antes da próxima extração. A fração alcoólica foi selecionada para os ensaios de corrosão, tendo em vista o fato de que os polifenóis (flavonoides), substâncias já identificadas na literatura como as principais responsáveis pela característica inibidora do chá verde serem solúveis em álcool. Ensaio realizado utilizando a reação de Shinoda [21] confirmou a presença de flavonoides no extrato testado. O extrato em etanol foi liofilizado (Figura 1b), de modo a retirar o solvente e se trabalhar com o produto seco, evitando a interferência do etanol nos ensaios de corrosão.

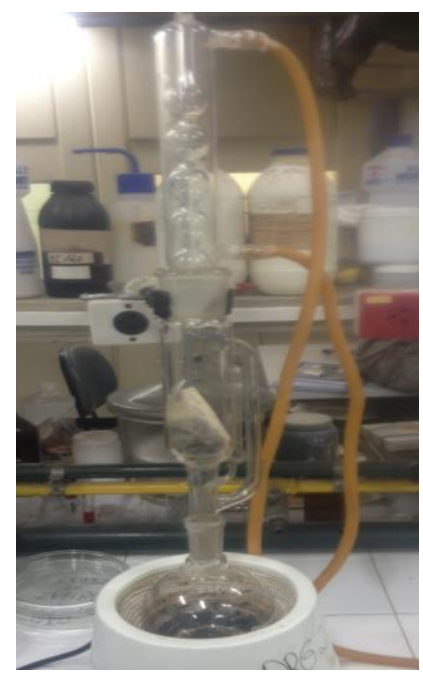

(a)

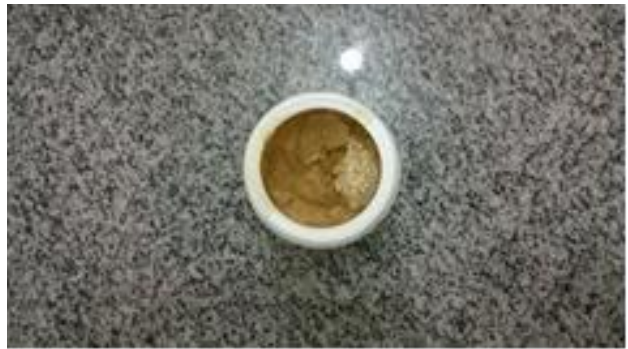

(b)

Figura 1: (a) Etapa de extração no aparelho tipo Soxhlet; (b) Extrato do chá branco em etanol após a etapa de liofilização. 
As taxas de corrosão $\left(\mathrm{W}_{\text {corr }}\right)$ foram obtidas a partir de ensaios gravimétricos (perda de massa) com uso do extrato liofilizado do chá branco em etanol (Eet), nas concentrações de 100, 200 e 300 ppm, realizados à temperatura de $25{ }^{\circ} \mathrm{C}$, em recipientes contendo $150 \mathrm{~mL}$ de $\mathrm{HCl}$ na concentração de 1 mol.L $\mathrm{L}^{-1}$, com duração de $2 \mathrm{~h}$. A perda de massa foi obtida em ensaios isolados, segundo a norma ASTM G1-03 [22], com a velocidade do processo corrosivo expressa a partir do cálculo da taxa de corrosão em milímetro por ano (mm.ano ${ }^{-1}$ ), mediante a equação (1):

$$
\mathrm{W}_{\text {corr }}=\frac{\mathrm{K} \times \mathrm{M}}{\mathrm{Ax} \times \mathrm{\rho}}
$$

Onde $\mathrm{K}$ representa uma constante $\left(8,76 \times 10^{4}\right)$, $\mathrm{M}$ a perda de massa em $\mathrm{g}$, A a área do corpo de prova em $\mathrm{cm}^{2}, \mathrm{t}$ o tempo de exposição em horas, e $\rho$ a massa específica do material em $\mathrm{g} / \mathrm{cm}^{3}\left(7,86 \mathrm{~g} / \mathrm{cm}^{3}\right)$.

A eficiência de inibição (EI) do extrato foi calculada a partir das taxas de corrosão obtidas no ensaio em branco $\left(\mathrm{W}_{\text {sem extrato }}\right)$ e nos ensaios com a presença do inibidor ( $\left.\mathrm{W}_{\text {com extrato }}\right)$, conforme a equação (2):

$$
\mathrm{EI} \%=\frac{\mathrm{W}_{\text {sem extrato }}-\mathrm{W}_{\text {com extrato }}}{\mathrm{W}_{\text {sem extrato }}} \times 100
$$

Os corpos de prova (aço P110) foram confeccionados na forma de retângulos com aproximadamente $2 \mathrm{~cm}$ de comprimento, $1 \mathrm{~cm}$ de largura, $0,5 \mathrm{~cm}$ de espessura e orifício central com $0,3 \mathrm{~cm}$ de diâmetro. Antes de cada ensaio os corpos de prova foram lixados (lixas de granulação 200 e 400 mesh), sendo então determinadas suas dimensões com auxílio de um paquímetro. Foram lavados e desengordurados com água destilada e detergente, e secos com uso de etanol e jatos de ar quente, antes e ao término de cada ensaio. A massa inicial e final de cada corpo de prova foi determinada em balança analítica com precisão de quatro casas decimais. Os ensaios foram realizados com o uso de dois corpos de prova, sendo utilizada a média dos valores obtidos.

Os ensaios de impedância eletroquímica (IE) e curvas de polarização (CP) anódica e catódica foram realizados em um potenciostato modelo Autolab, em uma célula eletroquímica convencional de três eletrodos: o aço carbono como eletrodo de trabalho, o eletrodo de calomelano saturado como eletrodo de referência e platina como contra-eletrodo. As curvas de polarização foram traçadas com velocidade de varredura igual a $1 \mathrm{mV} \cdot \mathrm{s}^{-1}$, com a eficiência de inibição (EI) sendo calculada a partir das densidades de corrente de corrosão conforme a equação (3), onde $\mathrm{I}_{\text {corr* }}$ equivale a densidade de corrente do ensaio em branco e $\mathrm{I}_{\text {corr }}$ representa a densidade de corrente na presença do extrato.

$$
\mathrm{EI} \%=\frac{\mathrm{I}_{\text {corr }^{*}}-\mathrm{I}_{\text {corr }}}{\mathrm{I}_{\text {corr }^{*}}} \times 100
$$

As medidas de IE foram realizadas no potencial de corrosão com regulação potenciostática na faixa de frequência de $100 \mathrm{kHz}$ a $10 \mathrm{mHz}$ e uma amplitude de perturbação igual a $10 \mathrm{mV}$. A capacitância da dupla camada elétrica $\left(\mathrm{C}_{\mathrm{dl}}\right)$ foi calculada a partir da equação (4), onde $\mathrm{f}_{\max }$ representa a frequência na qual a componente imaginária da impedância é máxima e $\mathrm{R}_{\mathrm{tc}}$ a resistência a transferência de carga.

$$
C_{\mathrm{dl}}=\frac{1}{2 \pi f_{\max } R_{t c}}
$$

A eficiência de inibição do extrato foi calculada a partir dos valores de resistência a transferência de carga, equação (5), onde $R_{t c *}$ representa a resistência a transferência de carga no ensaio em branco e $R_{t c} a$ resistência a transferência de carga na presença do extrato.

$$
\mathrm{EI} \%=\frac{\mathrm{R}_{\mathrm{tc}}-\mathrm{R}_{\mathrm{tc}}}{\mathrm{R}_{\mathrm{tc}}} \times 100
$$




\section{RESULTADOS E DISCUSSÃO}

A agressividade do meio corrosivo pode ser confirmada mediante os ensaios realizados na ausência do extrato testado (ensaio em branco), revelando para o aço P110 uma taxa de corrosão de 10,26 mm.ano ${ }^{-1}$ (Tabela 1). Observa-se que a adição do extrato do chá branco acarreta redução na velocidade do processo corrosivo, estando essa diminuição vinculada à concentração do inibidor.

A presença de $100 \mathrm{ppm}$ do extrato no sistema reduziu a taxa de corrosão para $1,47 \mathrm{~mm}$.ano ${ }^{-1}$, o que equivale a uma eficiência de inibição de $85,6 \%$, enquanto $200 \mathrm{ppm}$ do extrato proporciona uma taxa de corrosão de 1,14 mm.ano ${ }^{-1}$, indicando $88,9 \%$ de eficiência (Tabela 1). O melhor resultado foi identificado com o uso de $300 \mathrm{ppm}$ do extrato, que possibilita uma taxa de corrosão de $1,01 \mathrm{~mm} \cdot$ ano $^{-1}$, significando uma eficiência de inibição de $90,2 \%$.

Tabela 1: Valores da taxa de corrosão do aço carbono $\left(\mathrm{W}_{\text {corr }}\right)$, e eficiência de inibição (EI) do extrato do chá branco nas concentrações de 100, 200 e $300 \mathrm{ppm}$, em ensaios de $2 \mathrm{~h}$ na presença de $\mathrm{HCl} 1 \mathrm{~mol} \cdot \mathrm{L}^{-1}$ à $25^{\circ} \mathrm{C}$.

\begin{tabular}{c|c|c}
\hline $\begin{array}{c}\text { EXTRATO } \\
\text { (ppm) }\end{array}$ & $\begin{array}{c}\mathbf{W}_{\text {corr }} \\
\left.\text { (mm.ano }^{-1}\right)\end{array}$ & $\begin{array}{c}\text { EI } \\
(\%)\end{array}$ \\
\hline Branco & 10,26 & ----- \\
100 & 1,47 & 85,6 \\
200 & 1,14 & 88,9 \\
300 & 1,01 & 90,2 \\
\hline
\end{tabular}

Os percentuais de eficiência de inibição do extrato alcoólico do chá branco são comparáveis aos valores encontrados em trabalhos na literatura envolvendo o chá branco e os demais chás da Camellia sinensis [10,11,15-20], assim como de outras plantas [6,7, 23-31]. Vale destacar que uma avaliação mais abrangente entre os resultados dessa pesquisa e os dados de outros trabalhos apresenta restrições, devendo ser feita dentro do limite de comparação de comportamentos e tendências entre propriedades, uma vez que cada chá da Camellia sinensis, ou de qualquer outra planta, apresenta em sua composição metabólitos diferentes provenientes da natureza da planta e das condições empregadas na extração. A composição de um extrato depende de vários fatores, com a concentração dos metabólitos variando, por exemplo, mediante a quantidade e a parte utilizada da planta, e se essas são partes tenras ou maduras, da estação do ano, da temperatura e do horário na qual foram coletadas, além da natureza do solvente e da metodologia e/ou o tempo de extração. Cada extrato é único, só podendo ter seus resultados diretamente comparados com aqueles obtidos nas mesmas condições de extração. Além disso, pesquisas envolvendo extratos de plantas apresentam estudos com metais e meios corrosivos diferentes, com o uso de extrato seco ou na presença do solvente, fatores que influenciam nos resultados e dificultam as comparações.

No caso específico do trabalho de TEIXEIRA et al [20], onde foi empregado extrato aquoso do chá branco, valores de eficiência de inibição próximos de $90 \%$ foram obtidos com uma concentração de 1500 ppm do extrato, enquanto que para o extrato alcoólico identificamos a mesma faixa de inibição com uso de $300 \mathrm{ppm}$ do extrato. Isso não significa que o extrato alcoólico seja efetivamente melhor que o extrato aquoso, só revela que nas condições de extração usadas uma quantidade menor do extrato alcoólico é necessária para se obter a mesma faixa de eficiência de inibição do extrato aquoso, já que foram obtidos com uso de solventes diferentes e formas distintas de extração. Sem uma avaliação fitoquímica não é possível indicar os metabólitos que estão presentes em cada um dos extratos, ou prever diferenças na composição do extrato aquoso e do extrato alcoólico. Além da faixa de eficiência de inibição, outra comparação possível é a de que a presença de ambos os extratos acarreta a mesma tendência no comportamento dos valores de, por exemplo, $\mathrm{E}_{\text {corr }}$, $\mathrm{J}_{\text {corr }}, \mathrm{R}_{\mathrm{tc}}$ e $\mathrm{C}_{\mathrm{dl}}$, não sendo produtivo comparar numericamente esses valores.

Ao selecionar um extrato de planta para uso como inibidor de corrosão torna-se necessário observar aspectos de inibição do processo corrosivo e as condições necessárias para obtenção do extrato, verificando onde se alcança a melhor relação entre a eficiência inibidora e os gastos com os processos de produção do inibidor. Nesta pesquisa nos limitamos a avaliar a eficiência de inibição do extrato alcoólico do chá branco como potencial inibidor de corrosão em uma condição específica de uso.

Os ensaios eletroquímicos foram realizados com a presença de 300 ppm do extrato, por esta concentração apresentar a melhor eficiência de inibição. As curvas de polarização anódica e catódica, obtidas após a imersão dos corpos de prova na ausência (branco) e na presença do extrato são apresentadas na Figura 2.

A presença do extrato do chá branco acarretou a diminuição na densidade de corrente anódica e catódica, provavelmente devido à adsorção de substâncias presentes no extrato tanto nas regiões catódicas quanto 
nas anódicas da superfície do metal. A diminuição na densidade de corrente ocorreu em ambas as polarizações, observando-se uma redução mais significativa na corrente catódica.

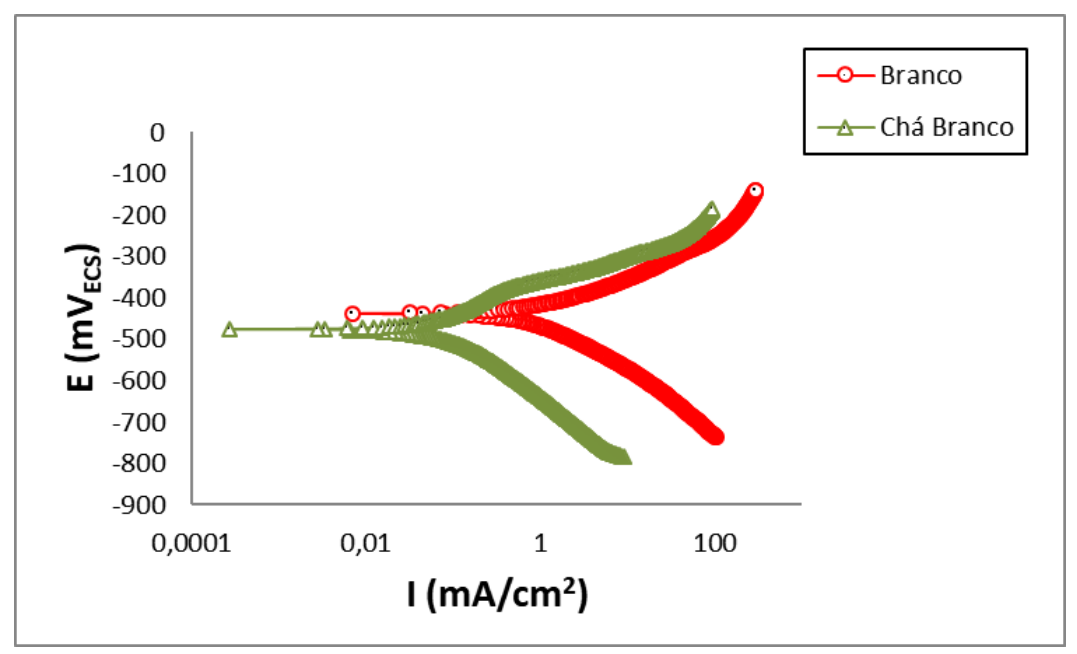

Figura 2: Curvas de polarização anódica e catódica obtidas para o aço carbono P110 em ácido clorídrico 1 mol.L $\mathrm{L}^{-1}$, na ausência e presença do extrato do chá branco na concentração de 300 ppm.

O potencial de corrosão do aço carbono no ensaio em branco foi de $-427 \mathrm{mV}$ (Tabela 2), sendo observado que a adição do extrato acarretou uma redução no valor do potencial de corrosão para $-493 \mathrm{mV}$, indicando um mecanismo de inibição característico dos inibidores de adsorção que costumam proporcionar pequeno deslocamento no potencial de corrosão. Verifica-se redução na densidade de corrente de corrosão frente ao branco, mediante a adição de 300 ppm do extrato (Tabela 2), com uma eficiência de inibição de $91,4 \%$.

Tabela 2: Valores do potencial de corrosão $\left(\mathrm{E}_{\text {corr }}\right)$, densidade de corrente de corrosão $\left(\mathrm{I}_{\text {corr }}\right)$ e eficiência de inibição (EI) para o aço carbono na presença de $\mathrm{HCl} 1 \mathrm{~mol} . \mathrm{L}^{-1}$ à $25^{\circ} \mathrm{C}$, na ausência e presença do extrato do chá branco na concentração de 300 ppm.

\begin{tabular}{c|c|c|c}
\hline $\begin{array}{c}\text { EXTRATO } \\
(\mathbf{p p m})\end{array}$ & $\begin{array}{c}\mathrm{E}_{\text {corr }} \\
(\mathbf{m V})\end{array}$ & $\begin{array}{c}\mathrm{I}_{\text {corr }} \\
\left(\mathbf{A} . \mathbf{c m}^{-2}\right)\end{array}$ & $\begin{array}{c}\text { EI } \\
(\%)\end{array}$ \\
\hline Branco & -427 & $3,20 \times 10^{-5}$ & ----- \\
300 & -493 & $2,75 \times 10^{-6}$ & 91,4 \\
\hline
\end{tabular}

O diagrama de impedância eletroquímica obtido para o aço carbono, na ausência e na presença do extrato é apresentado na Figura 3. O arco capacitivo indica a formação de um filme protetor com a adição de uma concentração de 300 ppm do extrato, acarretando aumento no valor da resistência a transferência de carga e redução na capacitância da dupla camada elétrica (Tabela 3).

Tabela 3: Valores de resistência do solvente $\left(R_{s}\right)$, resistência a transferência de carga $\left(R_{t c}\right)$, frequência máxima $\left(f_{\text {max }}\right)$, capacitância da dupla camada elétrica $\left(\mathrm{C}_{\mathrm{dl}}\right)$ e eficiência de inibição $(\mathrm{EI})$ para o aço carbono em $\mathrm{HCl} 1 \mathrm{~mol} \cdot \mathrm{L}^{-1}$ à $25^{\circ} \mathrm{C}$, na ausência e presença do extrato do chá branco na concentração de 300 ppm.

\begin{tabular}{c|c|c|c|c|c}
\hline $\begin{array}{c}\text { EXTRATO } \\
(\mathbf{p p m})\end{array}$ & $\begin{array}{c}\mathbf{R}_{\mathbf{s}} \\
\left(\boldsymbol{\Omega} . . \mathbf{c m}^{2}\right)\end{array}$ & $\begin{array}{c}\mathbf{R}_{\mathbf{t c}} \\
\left(\boldsymbol{\Omega} . . \mathbf{c m}^{2}\right)\end{array}$ & $\begin{array}{c}\mathbf{f}_{\max } \\
(\mathbf{H z})\end{array}$ & $\begin{array}{c}\mathbf{C}_{\mathrm{dl}} \\
\left(\mu . \mathbf{c m}^{-2}\right)\end{array}$ & $\begin{array}{c}\text { EI } \\
(\%)\end{array}$ \\
\hline Branco & 0,6 & 20,2 & 11,5 & 665 & ------ \\
300 & 2,0 & 407,3 & 6,6 & 59 & 95 \\
\hline
\end{tabular}




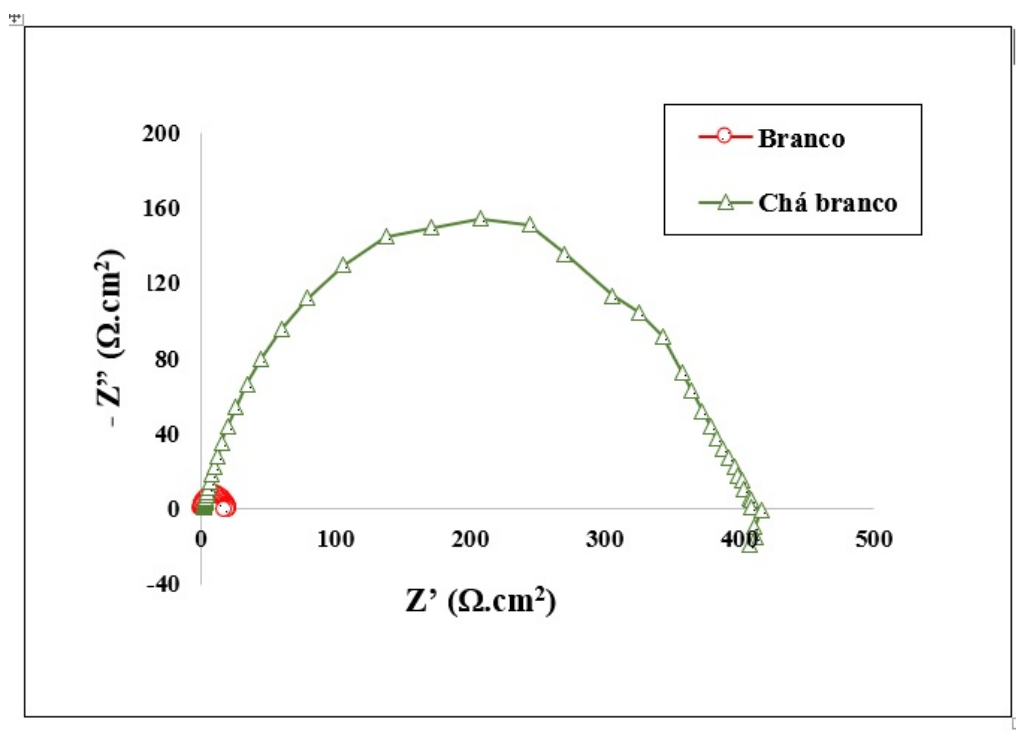

(a)

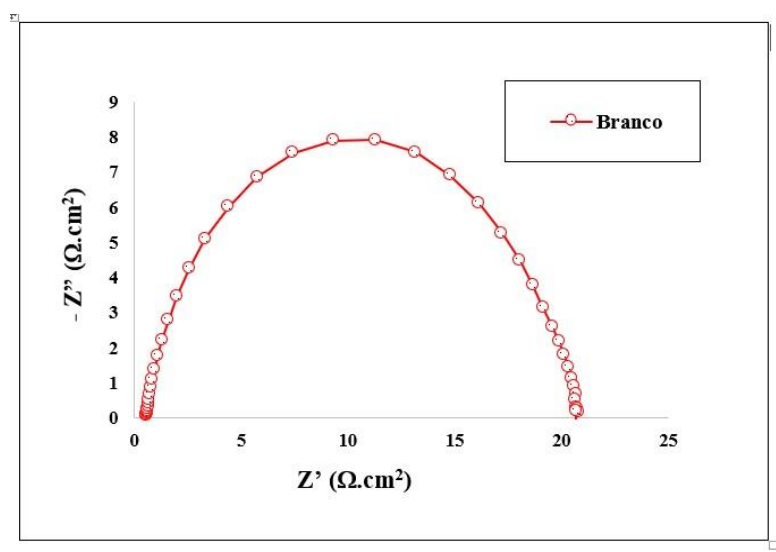

(b)

Figura 3: (a) Diagrama de impedância eletroquímica obtido para o aço carbono P110 em ácido clorídrico 1 mol.L $\mathrm{L}^{-1}$, na ausência e presença do extrato do chá branco na concentração de 300 ppm ; (b) Destaque para a curva na ausência do extrato do chá branco.

A eficiência de inibição foi calculada em $95 \%$ (Tabela 3), com o valor de $\mathrm{R}_{\mathrm{tc}}$ aumentando de 20,2 $\Omega . \mathrm{cm}^{2}$ no ensaio em branco, para 407,3 $\Omega . \mathrm{cm}^{2}$ na presença do extrato, e com redução nos valores de $C_{\mathrm{dl}}$ de $665 \mu . \mathrm{cm}^{-2}$ no ensaio em branco, para $59 \mu . \mathrm{cm}^{-2}$ com o uso de $300 \mathrm{ppm}$ do extrato. Estes dados corroboram a indicação de um processo de adsorção do extrato do chá branco sobre as áreas ativas do metal reduzindo o processo corrosivo.

\section{CONCLUSÕES}

Esta pesquisa teve como objetivo avaliar a eficiência de inibição do extrato liofilizado do chá branco em etanol, como potencial matéria ativa na formulação de inibidores de corrosão para o aço carbono P110 na presença de $\mathrm{HCl} 1$ mol.L $\mathrm{L}^{-1}$.

As taxas de corrosão indicam uma redução no processo corrosivo com a presença do extrato liofilizado, revelando uma eficiência de inibição de 90,2\% com o uso de uma concentração de 300 ppm.

A presença do extrato proporciona o deslocamento das curvas de polarização anódica e catódica frente ao branco, com redução nos valores de densidade de corrente e a respectiva redução na velocidade do processo corrosivo, com a curva catódica apresentando uma redução mais acentuada, sendo calculada uma eficiência de inibição de $91,4 \%$.

Os resultados de impedância eletroquímica foram significativos, com a formação de arco capacitivo, aumento na resistência a transferência de carga e redução na capacitância da dupla camada elétrica, revelando uma eficiência de inibição de $95 \%$. 
A adsorção de moléculas dos metabólitos presentes no extrato sobre a superfície metálica parece seguir o mecanismo que, em pH ácido, levaria a uma inibição tanto da dissolução metálica quanto da reação catódica de redução do hidrogênio. A inibição por adsorção das moléculas orgânicas sobre a superfície metálica explicaria os resultados experimentais apresentados, tais como o pequeno deslocamento do potencial de corrosão, a redução das correntes anódica e catódica, o aumento de $\mathrm{R}_{\mathrm{tc}} \mathrm{e}$ a diminuição nos valores de $\mathrm{C}_{\mathrm{dl}}$.

O extrato do chá branco testado apresenta-se como potencial matéria ativa na formulação de inibidor de corrosão para o aço carbono P 110 na presença de ácido clorídrico, fato relevante para uma possível aplicação industrial. Vale destacar que essa se trata de uma pesquisa inicial, com enfoque nos valores de eficiência de inibição em uma condição específica de uso, sendo necessária a realização de ensaios complementares visando avaliar a eficiência do extrato alcoólico do chá branco em condições diversas da empregada, envolvendo outros metais e variação do meio corrosivo e das condições operacionais, além do aprimoramento nas etapas de extração e liofilização de modo a tornar seu uso industrialmente aplicável.

\section{BIBLIOGRAFIA}

[1] JACKSON, J.E., Cost of Corrosion Annually in the US Over \$1.1 Trillion in 2016, G2MT Laboratories. SD, http://www.g2mtlabs.com/corrosion/cost-of-corrosion/. Acessado em fevereiro de 2017.

[2] MAGNANI, M., FUGIVARA, C. S., GARCIA, R., et al., "Cinética de dissolução da superfície de aço SAE-AISI 1005 em meio ácido.”, Eclética Química, v. 27, pp.113-124, 2002.

[3] POURBAIX, M., Lições de Corrosão Eletroquímica. $3^{\mathrm{a}}$ ed., Bruxelas, CEBELCOR, 1987.

[4] FELIPE, M.B.M.C., MACIEL, M.A.M., MEDEIROS, S.R.B., et al., "Aspectos gerais sobre corrosão e inibidores vegetais", Revista Virtual de Química, v. 5, n. 4, pp. 746-758, 2013.

[5] TORRES, V.V. Extrato de produtos naturais como inibidor de corrosão para o aço-carbono 1020, Dissertação de M.Sc., UFRJ, Rio de Janeiro, RJ, 2008.

[6] OLIVEIRA, T. M. ; ALVES, P. H. X. ; CARDOSO, S. P., "Produtos Naturais como inibidor de corrosão: avaliação do extrato da berinjela", In: 37 Reunião Anual da Sociedade Brasileira de Química, Natal, Maio, 2014.

[7] RAJA, P.B., SETHURAMAN, M.G., "Natural products as corrosion for metals in corrosive media - A review", Material Letters, v. 62, pp. 113-116, 2008.

[8] WANG, Y.C., CHUANG, Y.C., HSU, H.W., "The flavonoid and pectin content in peels of citrus cultivated in Taiwan", Food Chemistry, v. 106, pp. 277-284, 2008.

[9] INTERAGENCY TAXONOMIC INFORMATION SYSTEM. Camellia sinensis (L.) Kuntze. https://www.itis.gov/servlet/SingleRpt/SingleRpt?search_topic=TSN\&search_value=506801\#null. Acessado em novembro de 2017.

[10] LOTO, C.A., "Inhibition effect of Tea (Camellia Sinensis) extract on the corrosion of mild steel in dilute sulphuric acid.", Journal of Materials and Environmental Science, v. 2, n. 4, pp 335-344, 2011.

[11] MÜLLER. E.P. Efeitos dos chás verde e branco extraídos de folhas de Camellia sinensis sobre a viabilidade e o conteúdo de melanina de Células se melanoma murinho B16F10, Monografia de Graduação, UFPR Curitiba, PR, Brasil, 2008.

[12] MATSUBARA, S., RODRIGUEZ-AMAYA, D.B., "Teores de catequinas e teaflavinas em chás comercializados no Brasil”, Ciência e Tecnologia de Alimentos, v. 26, n. 2, pp. 401-407, 2006.

[13] RUSAK, G., KOMES, D., LIKIC, S., et al., "Phenolic content and antioxidative capacity of green and white tea extracts depending on extraction conditions and the solvent used", Food Chemistry, v. 110, pp. 852-858, 2008.

[14] VALENZUELA, A.B., "El Consumo te y la salud: características y propiedades benéficas de esta bebida milenária", Revista Chilena de Nutrición, v. 31, n. 2, pp. 72-82, 2004.

[15] FOUDA, A. E. S., MEKKIA, D., BADR, A.H., "Extract of Camellia sinensis as Green Inhibitor for the Corrosion of Mild Steel in Aqueous Solution,", Journal of the Korean Chemical Society, v. 57, n. 2, pp. 264271, 2013.

[16] RAMDI, T., ROSSI, S., ZANELLA, C., "Inhibition of the Cu65/Zn35 brass corrosion by natural extract of Camellia sinensis", Applied surface Science, v. 307, pp. 209-216, 2014. 
[17] LOTO, C.A., LOTO, R.T., POPOOLA, A.P.I., "Inhibition Effect of Extracts of Carica Papaya and Camellia Sinensis Leaves on the Corrosion of Duplex ( $\alpha \beta)$ Brass in 1M Nitric acid.", International journal of electrochemical Science, v. 6, pp. 4900-4914, 2011.

[18] LOTO, C.A., JOSEPH, O.O., LOTO, R.T., "Adsorption and inhibitive properties of Camellia sinensis for aluminium alloy in HCl", International journal of electrochemical Science, v. 9, pp. 3637-3649, 2014.

[19] GUDIC, S., EMEKA, E.O., RADONIC, A., et al., "Inhibition of copper corrosion in chloride solution by caffeine isolated from black tea.", Macedonian Journal of Chemistry \& Chemical Engineering, v. 33, n. 1, pp. 13-25, 2014.

[20] TEIXEIRA, V.M., SANTOS, E.C., REZENDE, M.J.C., et al., "Estudo da ação inibidora de extrato de Camellia sinensis na corrosão do aço-carbono $1020 \mathrm{em} \mathrm{HCl} 1$ molL $^{-1 "}$, Revista virtual de química, v. 7, n. 5, pp. 1780-1794, 2015.

[21] SOCIEDADE BRASILEIRA DE FARMACOGNOSIA. Flavonoides e Antocianos. 2014, http://sbfgnosia.org.br/Ensino/flavonoides_e_antocianinos.html. Acessado em fevereiro de 2017.

[22] ASTM G1-03. Standard practice for preparing, cleaning and evaluating corrosion test speciments, 2011.

[23] EL-ETRE, A.Y., ABDALLAH, M., EL-TANTAWZ, Z., "Corrosion inhibition of some metals using lawsonia extract”, Corrosion Science, v. 47, pp. 385-395, 2005.

[24] EL-ETRE, A.Y., "Inhibition of C-steel corrosion in acidic solution using the aqueous extract of zallouh root", Materials Chemistry and Physics, v. 108, pp. 278-282, 2008.

[25] SOUZA, F.S., SPINELLI, A., "Caffeic acid as green corrosion inhibitor for mild steel”, Corrosion Science, v. 51, pp. 642-649, 2009.

[26] PEREIRA, S.S.A.A., PEGAS, M.M., FERNANDEZ, T.L., et al., "Inhibitory action of aqueous garlic peel extract on the corrosion of carbono steel in HCl solution", Corrosion Science, v. 65, pp. 360-366, 2012.

[27] DENG, S., LI, X., "Inhibition by Ginkgo leaves extract of the corrosion of steel in $\mathrm{HCl}$ and $\mathrm{H}_{2} \mathrm{SO}_{4}$ solution", Corrosion Science, v. 55, pp. 407-415, 2012.

[28] ALENCAR, M.F., OLIVEIRA, L.R.F., GOMES, R.S., et al., "Extratos de plantas da Caatinga como inibidor de corrosão", In: $5^{\circ}$ Congresso Norte-Nordeste de Química, Natal, abril, 2013.

[29] UMOREN, S.A., GASEM, Z.M., OBOT, I.B., "Natural products for material protection: inhibition of mild steel corrosion by date palm seed extracts in acidic media", Industrial \& Engineering Chemistry Research, v. 52, 14855-14865, 2013.

[30] MATHINA, A., RAJALAKSHMI, R., "Corrosion inhibition of mild steel in acid medium using Canna Indica as green corrosion inhibitor", Rasayan Journal of Chemistry, v. 9, n. 1, pp. 56-66, 2016.

[31] FOUDA, A.S., MEGAHED, H.E., FOUAD, N., et al., "Corrosion inhibition of carbon steel in $1 \mathrm{M}$ hydrochloric acid solution by aqueous extract of Thevetia Peruviana", Journal of Bio and Tribo Corrosion, v. 2, n. 16, pp. 1-13, 2016.

\section{ORCID}

Thamires Matos de Oliveira Sheila Pressentin Cardoso http://orcid.org/0000-0003-3996-3624

http://orcid.org/0000-0002-1822-8420 